\title{
Deep slip rates along the Longmen Shan fault zone estimated from repeating microearthquakes
}

\author{
Le Li, ${ }^{1,2}$ Qi-fu Chen, ${ }^{1}$ Fenglin Niu, ${ }^{2}$ and Jinrong $\mathrm{Su}^{3}$ \\ Received 31 March 2011; revised 10 June 2011; accepted 23 June 2011; published 23 September 2011.
}

[1] We investigated deep slip rates along the Longmen Shan fault zone where the devastating 2008 M7.9 Wenchuan earthquake occurred using repeating earthquake data recorded by two digital seismic networks near the fault. Using cross-correlation analysis of waveform data, we identified a total of 231 doublets and 224 multiplets that have highly similar waveforms. Most of these sequences are aperiodic with recurrence intervals varying from a few minutes to hundreds of days. For each multiplet, we first constructed a reference seismogram at each station and used it to measure the delay time of the $\mathrm{P}$ and $\mathrm{S}$ waves of each event within the cluster. We used the delay times to determine the relative distances between each event and the cluster centroid. The relative distances were used in screening repeating events in each multiplet. We identified a total of 12 repeating earthquake clusters in the source region of the M7.9 Wenchuan earthquake. Most of the clusters are located at the edge of locked areas where large coseismic slips were observed during the 2008 Wenchuan earthquake, suggesting a close spatial relationship between microearthquakes and impending large devastating earthquakes. The measured in situ deep slip rates appeared to increase with depth and varied from 3.5 to $9.6 \mathrm{~mm} / \mathrm{yr}$ at depth range of $4-18 \mathrm{~km}$. They are approximately twice as large as those inferred from surface GPS and geological data. Our results here have significant implications to the understanding of faulting as well as risk assessment of seismic hazards.

Citation: Li, L., Q. Chen, F. Niu, and J. Su (2011), Deep slip rates along the Longmen Shan fault zone estimated from repeating microearthquakes, J. Geophys. Res., 116, B09310, doi:10.1029/2011JB008406.

\section{Introduction}

[2] The May 12, 2008, M7.9 Wenchuan Earthquake was the strongest and most devastating earthquake that struck China in the past thirty years. The earthquake ruptured within an imbricate thrust fault system developed as the frontal part of the Longmen Shan range between the steep eastern margin of the Tibetan Plateau and the western edge of the Sichuan Basin (Figure 1). The Tibetan Plateau is an actively deforming block resulting from the collision between Indian and Asia. GPS measurements in the region indicated that the Bayan Har block, as one of the active sub-blocks in the Tibetan Plateau, is moving toward northeast, at a rate of $\sim 21 \mathrm{~mm} / \mathrm{yr}$ (Figure 1) [Zhang et al., 2003, 2004]. It is, however, unclear whether these surface measurements reflect the subsurface slip rates within the range before the earthquake [Densmore et al., 2007].

[3] Repeating earthquakes are a series of special earthquakes regularly occurring almost at the same place. These earthquakes usually have approximately the same magnitude

\footnotetext{
${ }^{1}$ Institute of Earthquake Science, China Earthquake Administration, Beijing, China.

${ }^{2}$ Department of Earth Science, Rice University, Houston, Texas, USA.

${ }^{3}$ Earthquake Administration of Sichuan Province, Chengdu, China.

Copyright 2011 by the American Geophysical Union. 0148-0227/11/2011JB008406
}

with roughly the same repeating interval. They are commonly interpreted as repeated ruptures of a single asperity owing to the concentration stress caused by aseismic slips in the surrounding area [Vidale et al., 1994; Nadeau et al., 1995; Beeler et al., 2001]. The asperity is completely locked during the interseismic period. It is likely that small and isolated asperities within the aseismic slipping area are responsible for the occurrence of repeating microearthquakes. Under this assumption, deep slip rates can be estimated from coseismic slips of the repeating earthquakes [e.g., Nadeau and McEvilly, 1999; Igarashi et al., 2003; Rau et al., 2007], providing a direct in situ measurement of fault deformation at seismogenic depths.

[4] Repeating earthquakes have been observed at a wide range of tectonic environments, such as the San Andreas fault system [e.g., Nadeau et al., 1995; Nadeau and McEvilly, 1999; Schaff et al., 1998, 2002; Bürgmann et al., 2000; Peng et al., 2005], the northeastern Japan subduction zone [e.g., Igarashi et al., 2003; Uchida et al., 2003], the North Anatolian fault [Peng and Ben-Zion, 2006], the Taiwan arccontinent collision boundary [e.g., Rau et al., 2007; Chen et al., 2008]. Most of these repeating earthquakes were found at plate boundaries where the frequent occurrence of earthquakes generates a weak layer that allows continuous creeping for much part of the fault except for a few strong earthquake asperities. It is, however, unclear how pervasively these repeating microearthquakes occur in intraplate fault systems. 


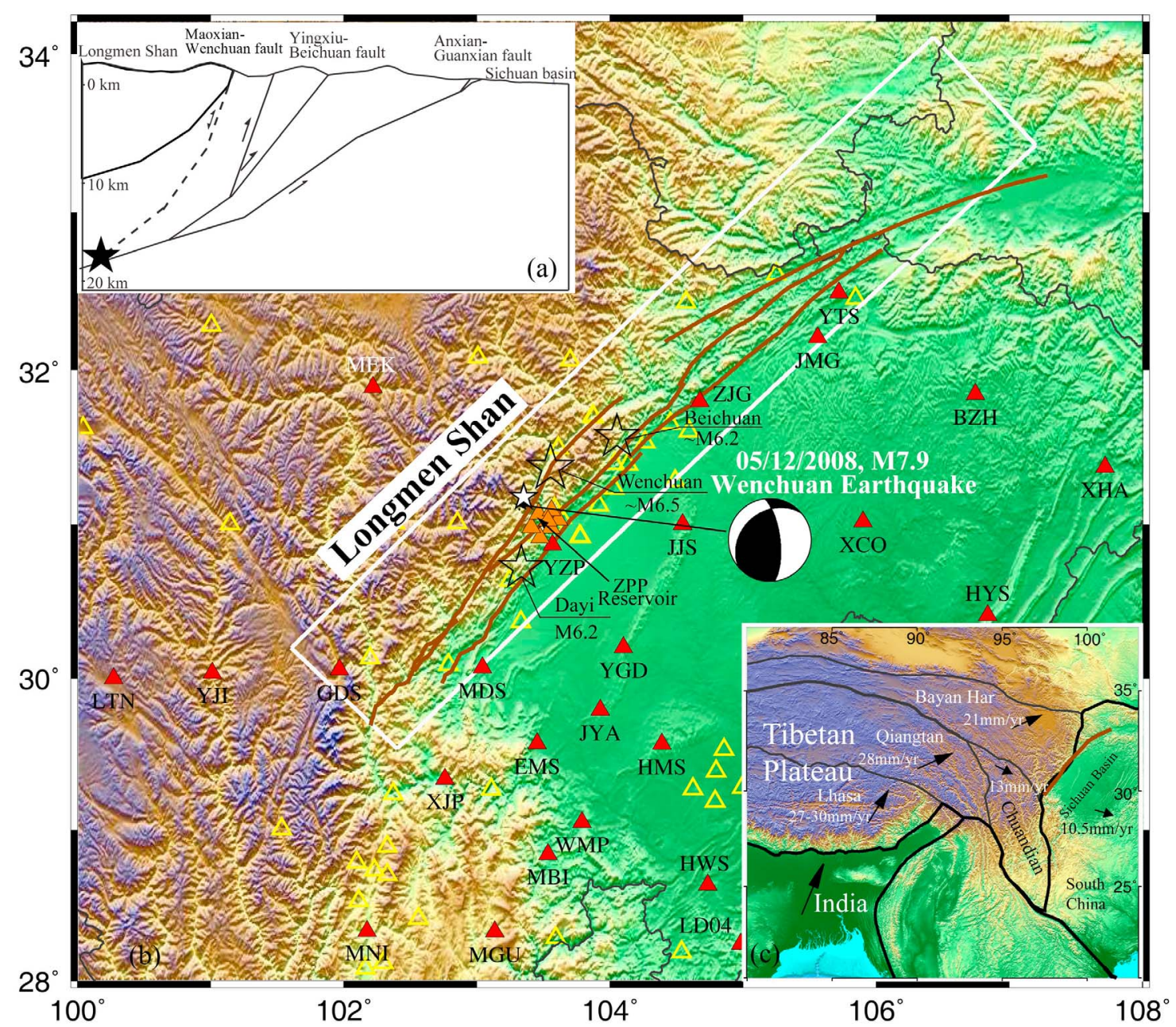

Figure 1. (a) A schematic cross section of the Longmen Shan fault zone. Star indicates the hypocenter of the M7.9 earthquake. (b) Geographic map showing the eastern margin of the Tibetan Plateau and the western Sichuan Seismic Basin. The white rectangle indicates the Longmen Shan fault zone, which is made up by three major faults (thick brown lines, see text for details). The white star and the beach ball indicate the epicenter and the focal mechanism of 2008 M7.9 Wenchuan earthquake. The SSN and ZRSN stations are shown by red and orange triangles, respectively. Analog stations of the SSN are indicated by yellow open triangles. The three black open stars represent the three $M>6$ historical earthquakes occurring before the 2008 Wenchuan earthquake. (c) Surface motions of the India plate and different blocks within the Tibetan Plateau relative to the stable Siberian craton.

[5] Using teleseismic waveform data, Schaff and Richards [2004] found that $\sim 10 \%$ of seismic events in Mainland China were repeating earthquakes. Li et al. [2007] analyzed local and regional waveform data recorded near the fault of the 1976 Mw7.6 Tangshan earthquake and found the microseismicity along the faults consisted of as much as $\sim 53 \%$ similar events. They also identified a few quasiperiodic sequences and used them to constrain the deformation rate of the fault. These observations led them the speculation that the fault generating the 1976 deadly earthquake in North China, though being an intraplate fault system, is actually mature enough to develop a weak layer essential for repeating earthquake. They further investigated another seismically active region in China, Yunnan Province. Based on two quasiperiodic sequences, Li et al. [2009] obtained the slip rate about $5 \mathrm{~mm} / \mathrm{yr}$ at $\sim 23 \mathrm{~km}$ depth of the Lijiang and Ninglang fault where several strong earthquakes occurred in the last ten years. The estimated slip rates at both locations appeared to be consistent with GPS measurements and geological data. In this study, we analyzed waveforms recorded by the Sichuan regional seismic network and the Zipingpu Reservoir seismic network to search for potential repeating microearthquakes along the Longmen Shan fault and to study the interseismic deformation across the fault.

\section{The Longmen Shan Fault System}

[6] The Longmen Shan fault system is a remarkable tectonic unit and geomorphological boundary. The topographic margin of the Tibetan Plateau along the Longmen Shan is one of the most impressive continental escarpments in the world: from the Sichuan Basin at 500 to 700 m elevation the 
land rises westward to peak elevations exceeding $6000 \mathrm{~m}$ over horizontal distances of 40-60 km [Burchfiel et al., 2008]. Influenced by the interaction between the eastward extruding Tibetan Plateau and the rheological strong Sichuan Basin, the Longmen Shan fault zone is composed of very complex structures that vary greatly along strike. A series of thrust faults were developed, which include the back-range Maoxian-Wenchuan thrust, the central Yingxiu-Beichuan thrust fault, and the front-range Anxian-Guanxian thrust fault (Figure 1). Different fault activities have been observed along these faults. These steeply dipping faults formed an imbricate thrust belt, and might merge at depth (Figure 1a) to accommodate shortening along the range front. Some of the slips were differed to detachments in the sedimentary basin according to topographic and geologic maps, and industry seismic reflection profiles [e.g., Jia et al., 2003; Burchfiel et al., 2008; Hubbard and Shaw, 2009; Xu et al., 2008; Liu et al., 2009; Xu et al., 2009].

[7] The Longmen Shan fault zone is located in the central segment of the North-South seismic zone of the Mainland China. The Longmen Shan seismic zone starts at Qingchuan in the north, through Beichuan, Maoxian, Wenchuan, Dujiangyan, Baoxing and Tianquan, and ends at Luding (Figure 1), extending approximately $400 \mathrm{~km}$ long and $70 \mathrm{~km}$ wide. GPS measurements before the earthquake found that active slip rate along the Longmen Shan fault zone was very low, at a few mm/yr [Zhang et al., 2004; Shen et al., 2005; Meade, 2007; Royden et al., 2008], or even less [Zhang et al., 2008]. This is somewhat consistent with the observed seismicity in the region. Seismicity along this seismic zone is generally restricted to small events $(M<5)$. Prior to the Wenchuan earthquake, the Longmen Shan thrust belt had been seismically quiet for several centuries; no earthquake with $\mathrm{M}>7$ was documented in the historical records. Only three earthquakes with $M>6$ were documented, i.e., Wenchuan M6.5 earthquake in 1657, Beichuan M6.2 earthquake in 1958 and Dayi M6.2 earthquake in 1970 [China Earthquake Administration, 1999] (Figure 1). The limited seismic activity and low deformation rate of the Longmen Shan seismic zone has led to moderate assessment of seismic hazard risk of this region.

\section{Identification of Repeating Earthquakes}

\subsection{Seismic Data}

[8] We found a total of 11171 events inside the Longmen Shan fault zone (Figure 1b) from the bulletins of the Sichuan Seismic Network (SSN) and Zipingpu Reservoir Seismic Network (ZRSN) between May 2000 and before the Wenchuan earthquake. Magnitudes of these events range from 0.1 to 4.2 in Richter magnitude scale. Among the 11171 events, 5246 events were recorded by the digital SSN from May 2000 to April 2008, and by ZRSN from August 2004 to April 2008. The two networks were instrumented with a mixed type of sensors and with a sampling rate of either 50 or $100 \mathrm{~Hz}$. The SSN started with a 14-station network in May of 2000 and gradually increased to 29 (red triangles in Figure 1b) in 2007. Most of the 29 stations are located inside the Sichuan Basin and only a few were installed in the Plateau side. Among the 29 stations, two stations, ZJG and YZP are located inside the fault zone and have a recording history back to 2000 . Besides the 29 digital stations, SSN is also operating 53 analog stations (open yellow triangles in Figure 1b) before 2008, which were also used in making the SSN bulletin. The ZRSN comprises of 7 tightly located stations (solid orange triangles in Figure 1b), which began operating in August 2004. It was designed to monitor seismicity around the Zipingpu reservoir.

\subsection{Search for Similar-Waveform Events}

[9] The data preprocessing applied to the raw waveform data includes the following steps: a $1-10 \mathrm{~Hz}$ bandpass filter was first applied to the data. The bandpass filtered data, which were digitized by a sampling rate of 50 or 100 samples per second, were then interpolated to a higher sampling rate for differential time measurement. Interpolation was performed in the frequency domain by packing additional zeros to the original spectrum. The sampling interval of the interpolated data is $0.3125 \mathrm{~ms}$, which was selected based on the uncertainty in the differential travel time measurement. The uncertainty is in principle determined by signal-to-noise ratio (SNR) of the waveform data [Cheng et al., 2007].

[10] We first began with the search of events that show similar waveforms using a cross-correlation (cc) method. We defined similar events to be event clusters that at least one station showed a $\mathrm{cc}>0.8$. We computed the $\mathrm{cc}$ with a time window $1 \mathrm{~s}$ before the $\mathrm{P}$ wave to $5 \mathrm{~s}$ after $\mathrm{S}$ wave. After scanning the entire waveform data set, we obtained 6427 event pairs with a cc $>0.8$ and further identified a total of 455 similar event sequences (Figure 2). Figure 3 shows an example of waveforms from a similar event sequence recorded at station ZJG. These sequences include 231 doublets consisting of two events and 224 multiplets having more than two events. The total number of earthquakes in the 455 sequences is 2419 , and the magnitude of these events ranges from $\mathrm{M}_{\mathrm{L}} 0.1$ to 3.9 (Figure $4 \mathrm{a}$ ).

[11] To characterize event variability, we calculated the recurrence intervals of each sequence and investigated their relationship with event magnitude given by the bulletins. We further computed the coefficient of variation (COV) of the event size and recurrence intervals in a sequence. $\mathrm{COV}$ is defined as the division of the standard deviation by the mean of the sequence. In general, sequences with a $\mathrm{COV}<1$ are considered as of low variance, while those with a COV $>1$ are considered to have significant variations. It appeared that events in each sequence showed less variation in size (Figure $4 \mathrm{~b}$ ) than in recurrence interval (Figure 4d).

[12] For regularity in the recurrence time, the low COV distribution is referred to as the quasiperiodic inter-arrival time distribution [Wu et al., 1995], a COV of 0 implies a perfect periodicity, $\mathrm{COV}=1$ implies Poissonian recurrence, which is unpredictable, and COV $>1$ indicates temporal clustering. The observed recurrence intervals shown in Figure $4 \mathrm{c}$ vary from a few minutes to hundreds of days. The COV distribution of recurrence interval for multiplets shown in Figure $4 \mathrm{~d}$ suggested a rather aperiodic feature of the observed similar event sequences. Most of the sequences lasted only a few days (Figure 4e), indicating that they were either earthquake swarms or aftershocks. Compared to those short-lived sequences, sequences with long duration showed less variation in recurrence interval, and more quasiperiodic features (Figure 4f). 


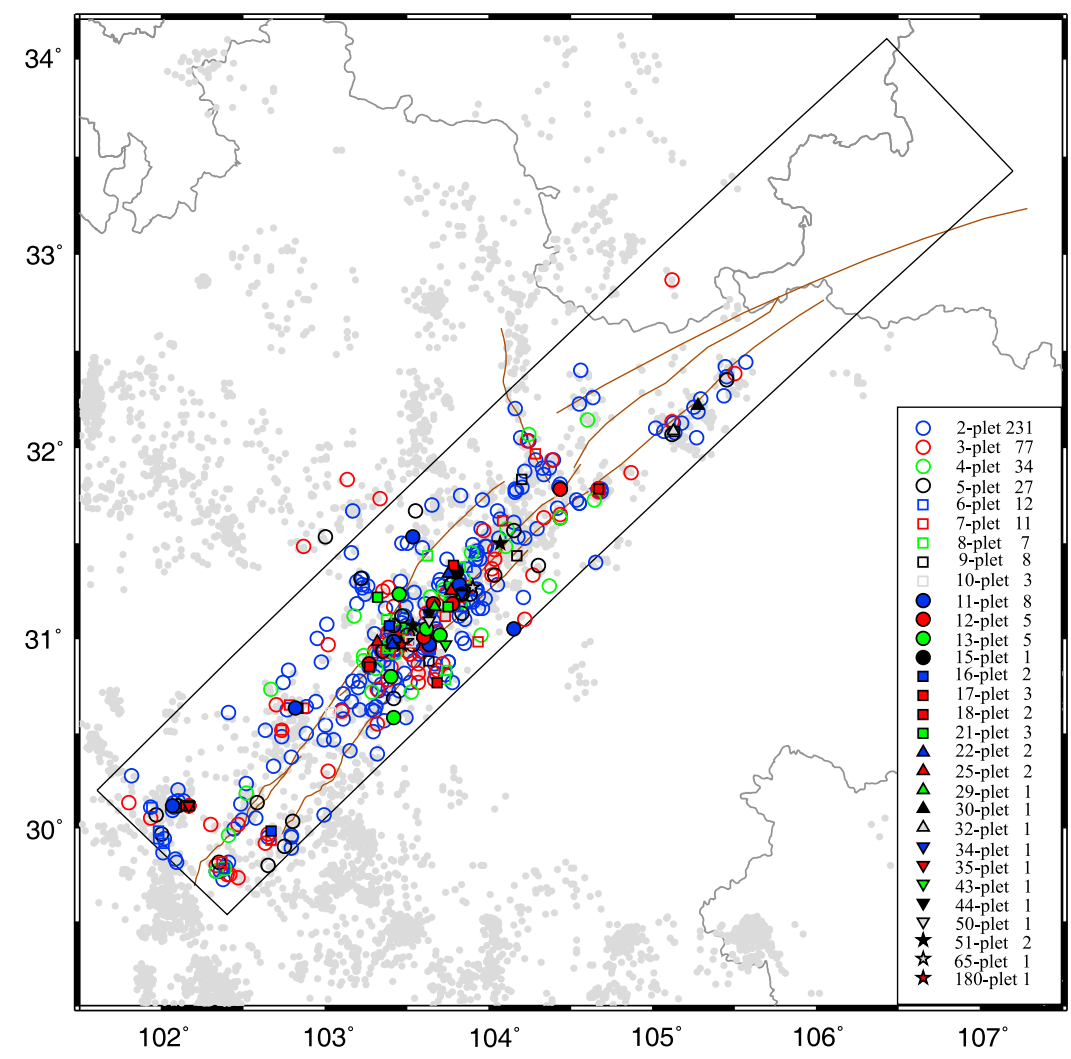

Figure 2. Map view of the identified similar event clusters. Grey circles represent the relocated background seismicity using the hypoDD method. These sequences are shown in different color symbols, with their corresponding doublets/multiplets indicated in the legend.

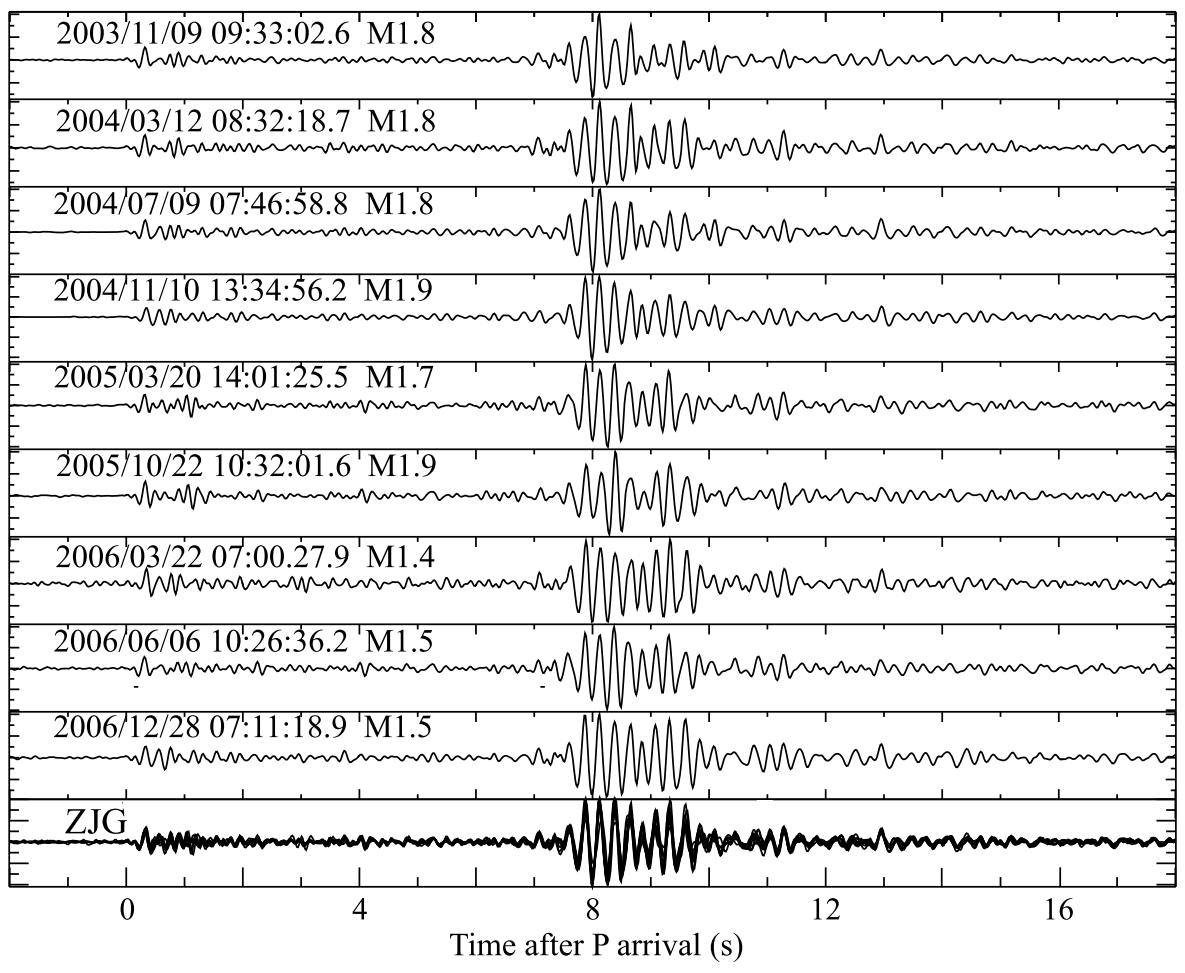

Figure 3. An example of seismograms from one similar event sequence recorded at the broadband station ZJG. Each trace was normalized by its maximum amplitude. The last row shows the overlap of all the seismograms. 

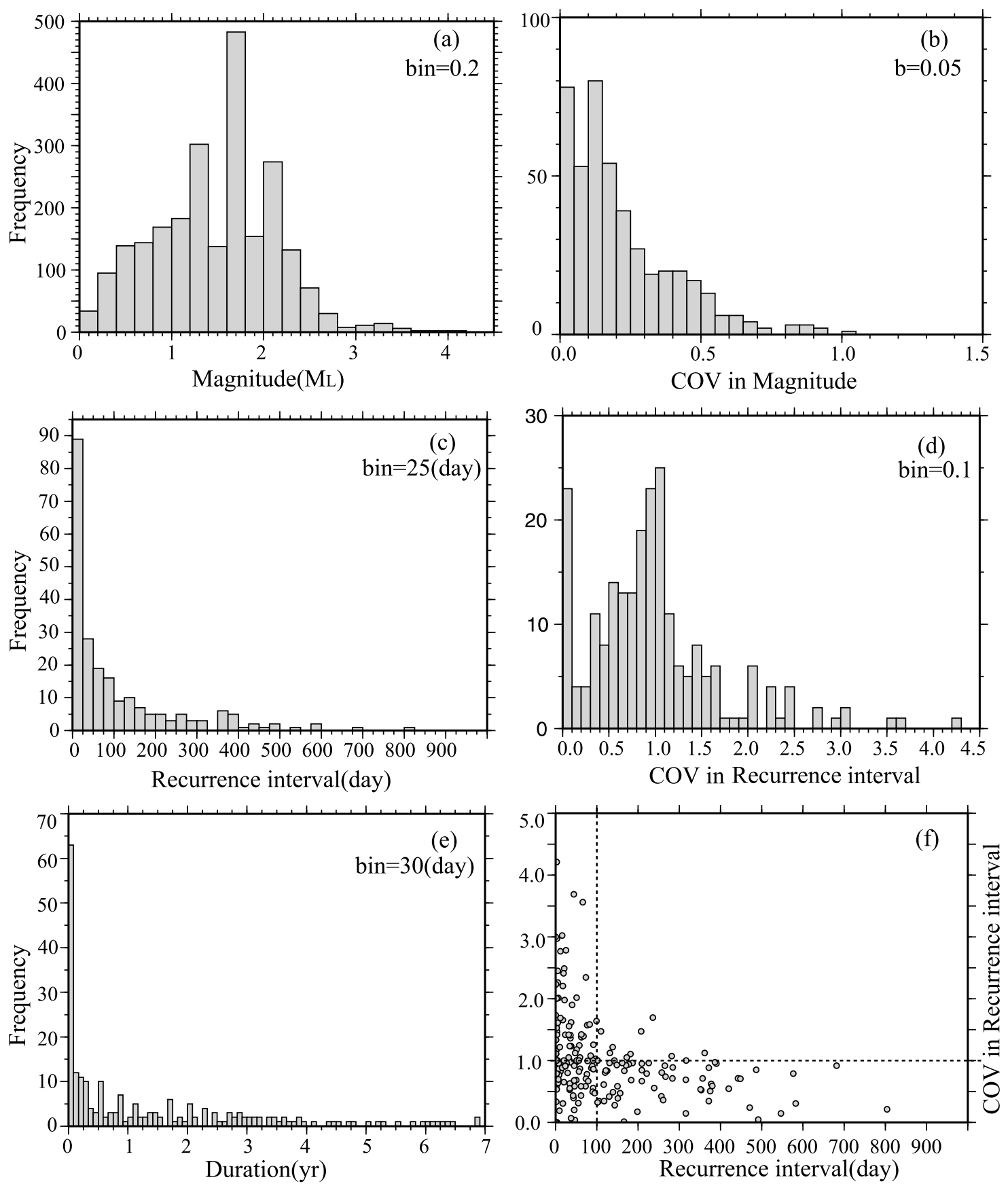

Figure 4. (a) Histogram of the magnitude distribution of similar events. (b) COV in magnitude for multiplets. (c) Histogram of recurrence interval for multiplets. (d) COV in recurrence intervals for multiplets. (e) Histogram of multiplet duration. (f) $\mathrm{COV}$ in recurrence interval for multiplets is shown as a function of the recurrence interval.

\subsection{Screening Repeating Earthquakes}

[13] Besides repeating earthquakes, earthquake swarms and immediate aftershocks have also been observed to exhibit very similar waveforms [e.g., Waldhauser et al., 1999; $L i$ et al., 2007]. The difference between repeating events and similar aftershock or swarm events is defined by their spatial distribution. It is likely that the similar events include both repeating events and similar aftershock or swarm events that do not occurred repeatedly, resulting in a large variance in recurrence interval. Thus it is necessary to accurately deter- mine the relative locations of earthquakes in each sequence and to separate repeating events from the similar ones [Rubin et al., 1999; Cheng et al., 2007; Li et al., 2007].

[14] Microearthquakes usually have fault dimensions of few tens meters, thus earthquakes within each sequence must be relocated with a high precision. This requires good azimuthal coverage of recording stations as well as accurate measurements of P- and S-wave delay times (at millisecond level). In our study region, most of SSN digital stations are situated in the eastern side of the Longmen Shan fault zone, resulting 
Table 1. Repeating Earthquake Sequences Identified Along the Longmen Shan Fault Zone

\begin{tabular}{|c|c|c|c|c|c|c|c|c|c|c|c|c|}
\hline \multirow[b]{2}{*}{ Sequence } & \multirow[b]{2}{*}{$\mathrm{N}^{\mathrm{a}}$} & \multicolumn{3}{|c|}{ Sequence Centroid Location } & \multirow[b]{2}{*}{$\mathrm{M}_{\mathrm{L}}$} & \multirow[b]{2}{*}{$\operatorname{Tr}^{\mathrm{b}}$ (years) } & \multicolumn{2}{|c|}{ Slip Rate $(\mathrm{mm} / \mathrm{yr})$} & \multirow[b]{2}{*}{$\begin{array}{l}\text { Total Slip } \\
\quad(\mathrm{mm})\end{array}$} & \multirow{2}{*}{$\begin{array}{c}\text { Sequence } \\
\text { Duration } \\
\text { (years) }\end{array}$} & \multicolumn{2}{|c|}{$\mathrm{COV}^{\mathrm{e}}$} \\
\hline & & $\begin{array}{l}\text { Longitude } \\
\text { (deg) }\end{array}$ & $\begin{array}{l}\text { Latitude } \\
\text { (deg) }\end{array}$ & $\begin{array}{c}\text { Depth } \\
(\mathrm{km})\end{array}$ & & & A_ $5^{\mathrm{c}}$ & $\mathrm{HK} \_3^{\mathrm{d}}$ & & & $\mathrm{M}_{\mathrm{L}}$ & $\operatorname{Tr}$ \\
\hline S01 & 7 & 102.3732 & 29.8132 & 8.4 & $1.6-2.3$ & $0.28-2.98$ & $3.9 \pm 0.6$ & $3.7 \pm 0.9$ & 31.6 & 6.41 & 0.11 & 0.95 \\
\hline S02 & 4 & 102.8489 & 30.6145 & 11.7 & $2.2-2.7$ & $1.14-1.65$ & $4.7 \pm 0.2$ & $5.4 \pm 0.6$ & 20.1 & 4.21 & 0.09 & 0.15 \\
\hline S03 & 5 & 103.2545 & 30.9057 & 6.2 & $1.3-2.1$ & $0.08-1.48$ & $5.4 \pm 1.3$ & $4.0 \pm 1.1$ & 16.3 & 2.76 & 0.20 & 0.79 \\
\hline S04 & 7 & 103.3037 & 31.1927 & 13.1 & $1.4-2.8$ & $0.04-1.81$ & $5.3 \pm 0.5$ & $5.3 \pm 0.7$ & 29.6 & 4.70 & 0.22 & 0.74 \\
\hline S05 & 4 & 103.6355 & 31.1870 & 4.0 & $1.5-1.9$ & $0.34-0.73$ & $6.8 \pm 0.6$ & $5.8 \pm 0.6$ & 11.3 & 1.59 & 0.09 & 0.30 \\
\hline S06 & 7 & 103.6741 & 31.1862 & 16.0 & $1.2-2.0$ & $0.02-1.07$ & $7.5 \pm 1.3$ & $6.0 \pm 1.6$ & 18.2 & 2.25 & 0.21 & 0.99 \\
\hline S07 & 9 & 103.7632 & 31.1779 & 14.3 & $1.3-2.8$ & $0.08-2.28$ & $5.3 \pm 0.8$ & $5.4 \pm 1.3$ & 37.4 & 5.52 & 0.22 & 0.97 \\
\hline S08 & 6 & 103.7177 & 31.2212 & 17.3 & $1.6-1.9$ & $0.02-1.11$ & $9.6 \pm 2.2$ & $6.8 \pm 2.4$ & 19.0 & 1.96 & 0.06 & 1.01 \\
\hline S09 & 4 & 103.8006 & 31.2996 & 10.5 & $1.4-2.0$ & $0.07-1.56$ & $4.7 \pm 1.2$ & $4.5 \pm 1.1$ & 10.4 & 2.04 & 0.16 & 0.94 \\
\hline $\mathrm{S} 10$ & 10 & 104.4335 & 31.7765 & 9.5 & $1.2-2.2$ & $0.06-1.60$ & $8.8 \pm 1.1$ & $7.9 \pm 1.3$ & 35.3 & 3.97 & 0.16 & 1.04 \\
\hline S11 & 9 & 104.4549 & 31.7604 & 4.3 & $0.9-1.8$ & $1.00-1.66$ & $3.8 \pm 0.4$ & $2.9 \pm 0.3$ & 23.9 & 5.56 & 0.24 & 0.84 \\
\hline $\mathrm{S} 12$ & 5 & 104.4464 & 31.8238 & 4.6 & $1.4-1.8$ & $0.45-1.76$ & $3.5 \pm 0.6$ & $4.0 \pm 0.5$ & 14.2 & 3.87 & 0.10 & 0.52 \\
\hline
\end{tabular}

${ }^{\mathrm{a}}$ Number of earthquakes in one sequence.

${ }^{\mathrm{b}}$ Recurrence interval.

${ }^{c}$ Estimates with Abercrombie's $\mathrm{M}_{\mathrm{L}}-M_{0}$ relationship and $5 \mathrm{MPa}$ coseismic stress drop

${ }^{\mathrm{d}}$ Estimates with Hanks-Kanamori's $\mathrm{M}_{\mathrm{L}}-M_{0}$ relationship and $3 \mathrm{MPa}$ coseismic stress drop.

${ }^{\mathrm{e}} \mathrm{Coefficient}$ of variance in recurrence interval and magnitude.

in a one-side distribution to the earthquakes occurring in the study area. We thus only chose multiplets whose waveforms showed high similarity with a high SNR to perform further relative relocation.

[15] We applied the following criteria to select multiplets: (1) an average cc is $>0.9$; (2) internal inconsistency in travel time picking is $<0.5 \mathrm{~ms}$ [Cheng et al., 2007]; (3) average recurrence interval is $>100$ day (Figure 4f). The internal inconsistency in delay time estimate can be regarded as an index of measurement error. Similar earthquake sequences with short recurrence intervals have been interpreted to represent a triggering or micro-aftershock process occurring on closely spaced but not overlapping fault patches. The restriction on the recurrence interval is emplaced to reduce the risk of misidentifying similar events to repeat ones. As shown in Figure 4f, most of similar sequences with recurrence intervals greater than 100 days showed a low $\mathrm{COV}$, we thus used it in selecting similar/repeating event sequences. We found a total of 18 multiplets satisfying the above criteria.

[16] To determine relative location of earthquakes in one sequence, we first constructed a reference seismogram at each station. The reference seismogram is simply an average seismogram of the linearly stacked trace of all the events. It can be considered as the recording as if an earthquake occurred at the centroid of the multiplet. Then we measured the delay times of $\mathrm{P}$ and $\mathrm{S}$ waves relative to the reference seismogram for each earthquake in a sequence at all the stations. We applied the fine relocation method [Got et al., 1994] to obtain the relative locations between each event and the sequence centroid. Among the 18 sequences, 13 sequences had reasonable station coverage and were relocated. We further assumed a circular rupture area for each earthquake and computed the radius based on its magnitude. Details on the computation are given in the next section. All the earthquakes are assumed to have occurred on the fault plane, and we compared their relative distance with rupture sizes. We found no overlap of rupture areas within 4 sequences. The other 9 sequences (S01, S02, S03, S04, S05, S06, S07, S08, and S09 in Table 1) had at least significant overlap among their members. Figure 5 shows two examples of the lateral distribution of the relocated events in the sequence S01 and S04. In each plot, earthquakes are shown as a circle with a radius proportion to the rupture area. Calculation of rupture area will be described in the next section. All the events in sequence S01 overlapped with each other (Figure 5a), while the events $1,3,4,6,8$ and 9 in clusters S04 are outliers as they barely overlap with the reference event (Figure 5b). The average magnitude of a sequence is used in computing the reference circle. The measured S-P time has an error of $\sim 0.3 \mathrm{~ms}$, which converts to a $\sim 10 \mathrm{~m}$ error in the relative locations. We counted this uncertainty when we determine whether or not an event overlaps with the reference circle.

[17] Due to the lack of seismic stations in the northeast section of the fault, we found the 5 sequences occurring in the Beichuan region were poorly recorded. The station azimuthal coverage was not good enough to allow us to obtain decent relocation accuracy. For these sequences, we developed an empirical way based to the S-P differential time, $\Delta \mathrm{t}_{s-p}$, to constrain the relative distance between event pairs. We used this method to determine the event members in these sequences.

[18] As shown in Figure 6, if the centroid of a sequence is located at $\mathrm{R}$ from a station, and an earthquake is displaced by $\Delta \vec{x}$ from the centroid,

$$
\vec{R}^{\prime}=\vec{R}+\Delta \vec{x}
$$

Since all the events inside a sequence are closely located, i.e., $\Delta x \ll R$, the $\mathrm{P}$ - and $\mathrm{S}$-wave delay time with respect to the reference seismogram can calculated by

$$
\begin{aligned}
\Delta t_{p} & =t_{p}^{\prime}-t_{p}=\frac{|\vec{R}+\Delta \vec{x}|}{v_{p}}-\frac{|\vec{R}|}{v_{p}} \\
& =\frac{|\vec{R}|}{v_{p}} \sqrt{1-\frac{2|\Delta \vec{x}| \cos \theta}{|\vec{R}|}+\frac{|\Delta \vec{x}|^{2}}{|\vec{R}|^{2}} \cos ^{2} \theta}-\frac{|\vec{R}|}{v_{p}} \\
& \approx-\frac{|\Delta \vec{x}| \cos \theta}{v_{p}} \\
\Delta t_{s} & \approx-\frac{|\Delta \vec{x}| \cos \theta}{v_{s}}
\end{aligned}
$$



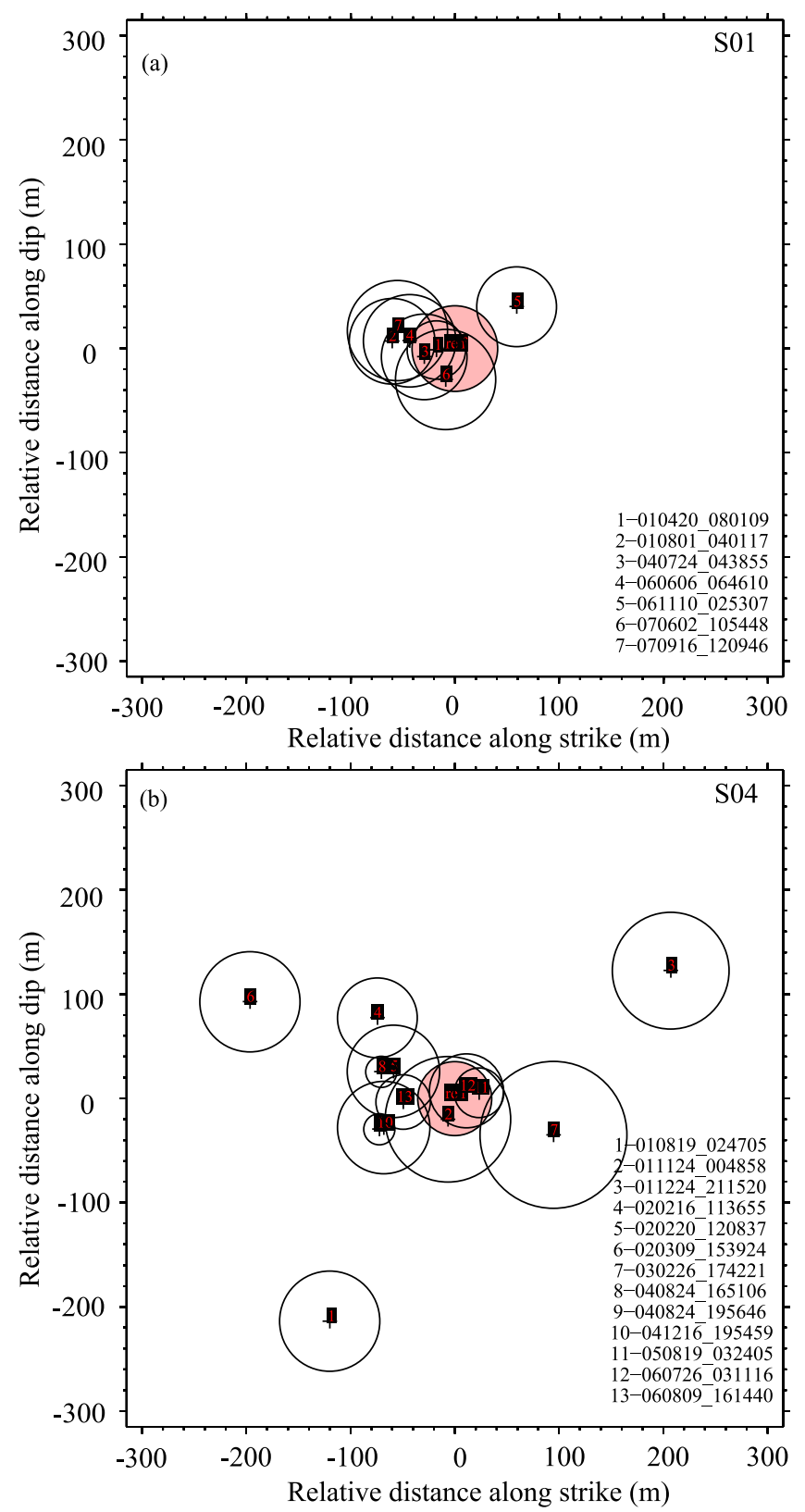

Figure 5. Map views of the relative locations of events in the (a) S01 multiplet and (b) S04 multiplet. All the events in S01 multiplet overlap with each other, while the events 1 , $3,4,6,8$ and 9 in clusters S04 barely overlap with the reference event and were eliminated from the sequence S04.

Here $\theta$ is the angle between the vectors $\vec{R}$ and $\Delta \vec{x}$. The relative S-P differential time can be approximated as

$$
\begin{aligned}
\Delta t_{s-p} & =\Delta t_{s}-\Delta t_{p}=-\left(\frac{1}{v_{s}}-\frac{1}{v_{p}}\right) \cos \theta|\Delta \vec{x}| \\
& =-\frac{|\Delta \vec{x}|}{v_{p}}\left(\frac{v_{p}}{v_{s}}-1\right) \cos \theta=-\frac{|\Delta \vec{x}|}{v_{p}}(\gamma-1) \cos \theta
\end{aligned}
$$

Here $\gamma$ is the ratio of the P- and S-wave velocity.

$$
\Delta x \geq \frac{v_{p} \Delta t_{s-p}}{\gamma-1}
$$

Assuming $V_{P}=6.0 \mathrm{~km} / \mathrm{s}$ and $\gamma=1.7$, we obtained

$$
\Delta x \geq 8.6 \Delta t_{s-p}
$$

When the relative distance is less than the rupture sizes, $\left(\Delta x<r+r^{\prime}\right)$, we consider the event as a possible candidate of repeating earthquake (Figure 6). On the other hand, if $\Delta x>r+r^{\prime}$ or $\Delta t_{S-P}>\left(r+r^{\prime}\right) / 8.6$, then the event is discarded from the sequence. Using the measured $\Delta t_{S-P}$, we identified 3 repeating earthquake sequences (S10, S11, and S12 in Table 1) in the Beichuan area.

[19] As shown in equation (5), we need to estimate rupture size in order to determine whether an earthquake is a repeating event or not. In principle, rupture size can be estimated from the magnitude of the earthquake. Event magnitude in the SSN catalog is given in Richter scale. To determine event magnitude, digital recordings were first convolved by the instrument response of a Wood-Anderson seismograph, followed by a correction of attenuation structure. As a complementary way of measuring earthquake size, and also a verification of magnitude given in the catalog, we used a spectral ratio method [Vidale et al., 1994] to determine the relative size of the events in each sequence. Seismograms of all events in a multiplet were first assembled at a given station. Amplitude spectra were then computed from a $20 \mathrm{~s}$ time window that includes both $\mathrm{P}$ and $\mathrm{S}$ waves. These spectra were further stacked to form a station average, which was used to normalize the individual spectrum. The normalized spectra, the spectral ratio, were computed for every station and event. The spectral ratios were reassembled on event base and were subsequently averaged to form an event spectra ratio. The relative moments are finally measured from the spectral ratios averaged in the frequency range of 1 to $10 \mathrm{~Hz}$. We calculate the relative moments for all the 12 repeating earthquake sequences. As shown in Figure 7, there is a linear correlation between the logarithm of relative moment and local magnitude $M_{L}$, indicating that event magnitude in the SSN catalog is well determined.

[20] We used the moment-magnitude relationship of Abercrombie [1996]

$$
\log \left(M_{0}\right)=9.8+M_{L}
$$

to convert the local magnitude, $M_{L}$, to the scalar moment, $M_{0}$. We assumed a circular rupture model and estimate the rupture radius, $r$, from $M_{0}$ using the scaling rule introduced by Kanamori and Anderson [1975]:

$$
r=\left(\frac{7 M_{0}}{16 \Delta \sigma}\right)^{1 / 3}
$$

Liu et al. [2010] measured coseismic stress drops of 323 $M_{\mathrm{L}} 3.0-5.1$ earthquakes occurring in the Longmen Shan fault zone and obtained an average value of $\sim 5 \mathrm{MPa}$. Thus we employed stress drop $(\Delta \sigma)$ of $5 \mathrm{MPa}$ in our calculation of rupture size from the seismic moment, $M_{0}$.

[21] Using the above two methods, we identified a total of 12 repeating earthquake clusters from the 18 similar events sequences. The 12 sequences included 77 earthquakes, which account for $1.5 \%$ of the total seismicity (5246). On the other hand, we identified 231 doublets and 224 multiplets that 


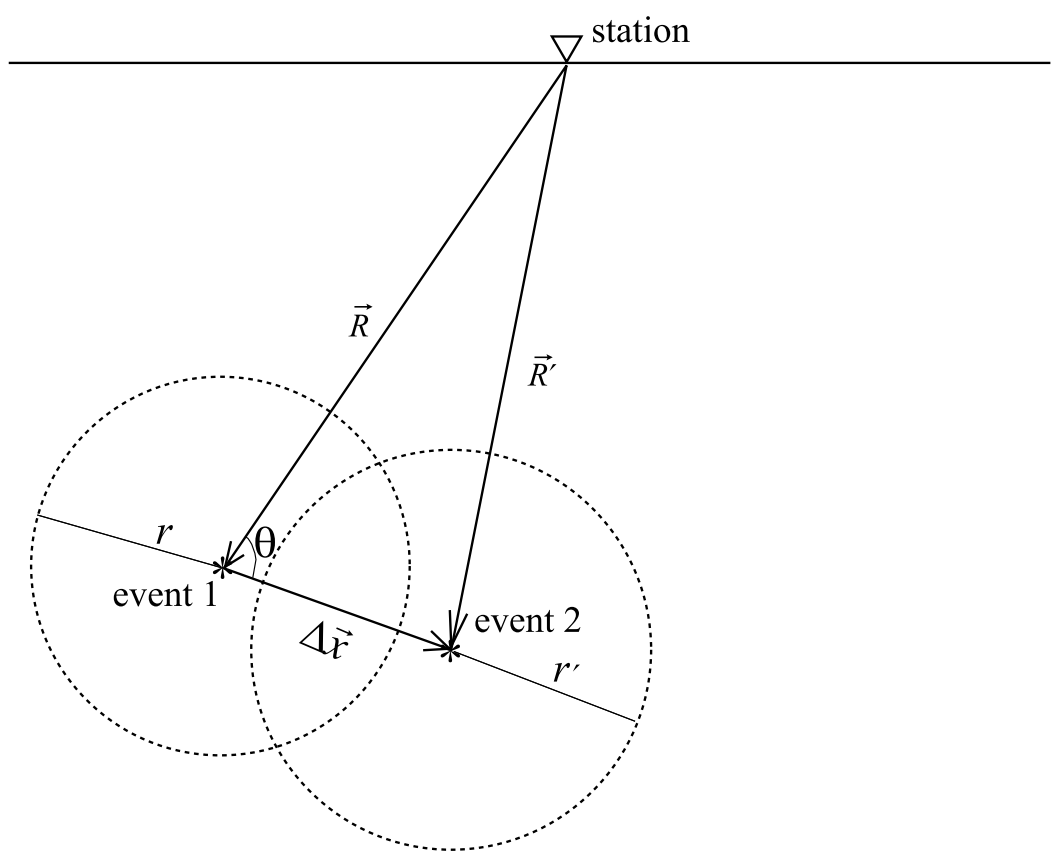

Figure 6. A schematic diagram illustrating the triangular relationship among the three vectors, $\vec{R}, \vec{R}^{\prime}$, and $\Delta \vec{x}$.

include a total of 2419 events. This may suggest that almost half of the seismicity occurs in regular patches.

[22] We noticed that in each sequence the occurrence of the earthquakes are rather aperiodic, and there are also significant variations in magnitude (Figure 8). This irregularity may reflect the complex nature of slip behavior within the fault. As noted before, the SSN was evolving from a 14-station to 29-station network. Thus the irregularity may also be caused by misidentification of repeating events in each sequence. The problem is twofold: some of the similar earthquakes could be mislabeled as repeating events, and some of the members could be overlooked, because of the difficulties in determining the accurate locations and sizes of the earthquakes. The latter could lead to an underestimate of the actual slip rate. Repeating intervals tend to drop significantly, leading to very high estimates of slip rate after major earthquakes [e.g., Schaff et al., 1998; Taira et al., 2008]. The observed high slip rates here are, however, unlikely to be biased by this post seismic effect as we didn't include any aftershock data in this study. It will be interesting to see whether and how the repeating-earthquake properties of these 12 sequences changed with the M7.9 Wenchuan earthquake.

\subsection{Relocation of the Background Seismicity}

[23] Event locations in the SSN catalog were routinely determined from picks of $\mathrm{P}$ - and $\mathrm{S}$-wave arrival times. The relocation method used is hypo71 or hypo2000 with a 1-D velocity model comprising two flat uniform layers. Typical error in location is in the order of a few kilometers to a couple tens of kilometers. It is thus necessary to relocate the repeating earthquakes for further analysis. To relocate earthquakes with an improved precision, we first employed a 6-layer 1D velocity model derived from Depth Seismic Sounding (DSS) profile studies [Zhao et al., 1997] and used hypo2000 to re-determine their absolute location. We then used the double difference (DD) method [Waldhauser and Ellsworth, 2000] to better relocate the relative locations of the entire seismicity. The DD method minimizes residuals between the observed differential times measured from pairs of earthquakes at each station and those calculated times. Instead of locating each event individually, the DD method is designed to derive a set of locations that best fit the relative travel times among the entire seismicity, especially when accurate differential travel-time data are available from waveform cross correlation.

[24] We calculated the cross correlation and the differential time in the time domain using a $1.1 \mathrm{~s}$ time window $(0.1 \mathrm{~s}$

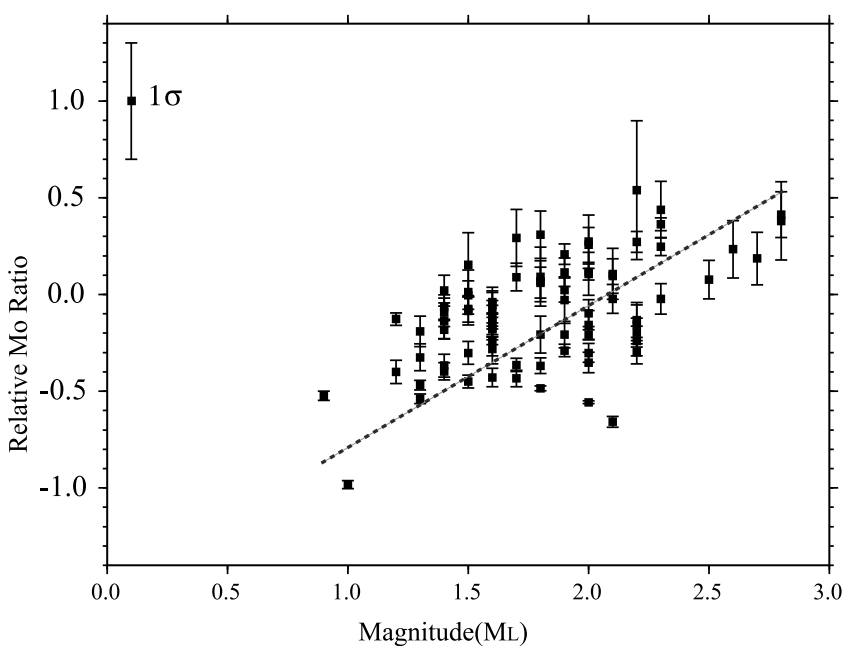

Figure 7. Relative moment ratios (logarithm) calculated from the spectral ratio method are shown as a function of local magnitude given by the catalog. Notice the linear correlation between the two. 


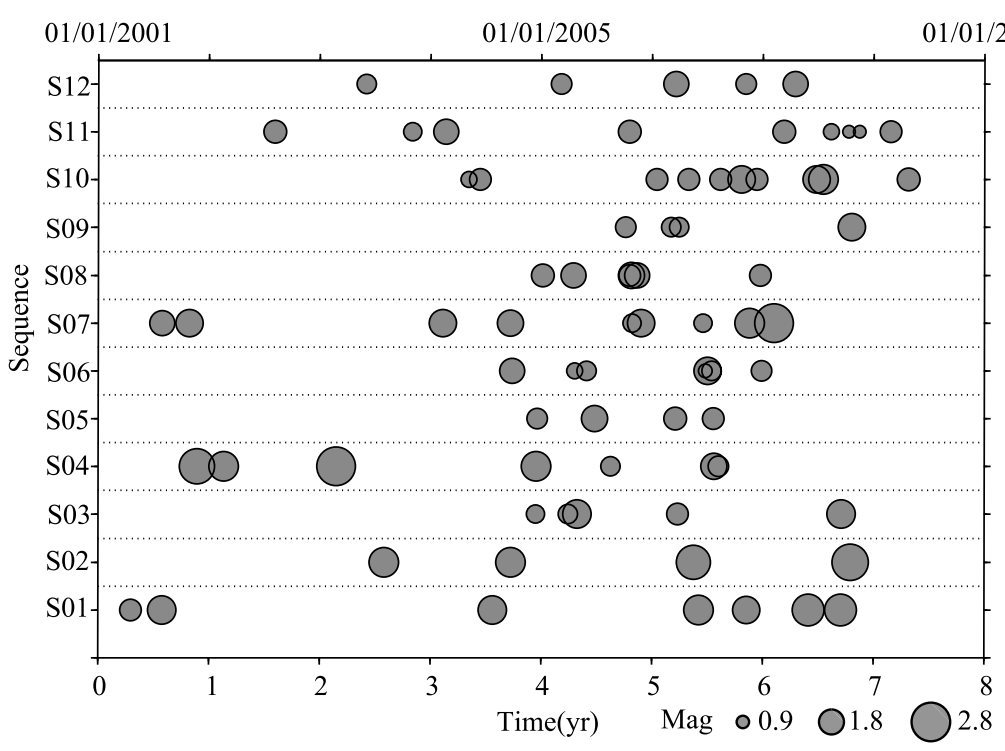

Figure 8. Occurrence times of the earthquakes in the 12 sequences. Symbol size is proportional to magnitude of the earthquakes.

and $1.0 \mathrm{~s}$ before and after the onset of the $\mathrm{P}$ wave, respectively). To ensure the time window is correctly selected, we manually picked $\mathrm{P}$ wave arrival times from waveform data with high SNR. We also manually verified the catalog picks of $\mathrm{P}$ wave and $\mathrm{S}$-wave arrival and replaced these picks with more accurate ones. We imposed a threshold of $\mathrm{cc}>0.7$ in selecting event pairs to calculate the differential travel times for DD relocation. These high quality differential travel time data were added to the refined bulletin data recorded by the digital stations and analog stations in the DD relocation analysis.

[25] The relocation of hypocenters of the microearthquakes further requires a suitable velocity model. As mentioned above, the Longmen Shan fault zone is located in a sharp boundary between the Tibetan Plateau and Sichuan Basin. The two tectonic units differ significantly in geologic and seismic structure. Many studies found substantial differences in crustal thickness and seismic velocity between the east and west sides of the fault zone. For example, crust underneath the Plateau side is $\sim 20 \mathrm{~km}$ thicker than those beneath the basin. This could cause significant location error when a $1 \mathrm{D}$ velocity model is used in calculating travel times. We thus employed two 1D velocity models in relocating the earthquakes with the revised hypoDD code [Huang et al., 2008]. The two 1D velocity models were shown in Table 2. We used them to calculate travel time for stations located in the two sides of the fault.

\section{In Situ Measurement of Deep Slip Rates}

[26] Nadeau and Johnson [1998] estimated moment release rates at the Parkfield section of the San Andreas and found that the determined slip rates are in good agreement with geodetic measurements of tectonic loading rate along the fault. The identification of 12 repeating sequence along the Longmen Shan fault zone thus provides a unique opportunity to estimate the in situ slip rates at seismogenic depths.
Once the rupture size was estimated, the coseismic slip can be calculated from the estimated seismic moment $\left(M_{0}\right)$ and rupture size $(r)$ :

$$
d=M_{0} / \mu \pi r^{2}
$$

[27] Here the shear modulus $\mu$ is taken to be $3 \times 10^{10} \mathrm{~N} / \mathrm{m}^{2}$. We obtained annual slip rate using a linear regression of the cumulative slip for each repeating event sequence.

\section{Results and Discussion}

[28] The estimated slip rate varies from 3.5 to $9.6 \mathrm{~mm} / \mathrm{yr}$, with a mean and median of $5.8 \mathrm{~mm} / \mathrm{yr}$, and $5.3 \mathrm{~mm} / \mathrm{yr}$, respectively (Table 1 and Figure 9). The uncertainty in measuring slip rates is estimated to be from 0.2 to 2.2 (Figure 9). We found that the standard deviation of the estimated slip rate decreased with duration, indicating that the slip rates estimated from repeating earthquake sequences with a short duration are less accurate than those of the long-lived sequences.

[29] The estimated slip rates depend highly on the assumed empirical relationship between magnitude $\left(M_{\mathrm{L}}\right)$ and moment $\left(M_{0}\right)$, as well as the assumed value of coseismic stress drop. For comparison, if we use Hanks and Kanamori's [1979] (HK) empirical relationship $\left(\log \left(M_{0}\right)=16.1+1.5 M_{L}\right)$,

Table 2. The Alternate Model Used in the Study

\begin{tabular}{ccccc}
\hline \multicolumn{2}{c}{ West Area $(\mathrm{Vp} / \mathrm{Vs}: 1.68)$} & & \multicolumn{2}{c}{ East Area $(\mathrm{Vp} / \mathrm{Vs}: 1.78)$} \\
\cline { 5 - 5 } $\begin{array}{c}\text { Top Depth } \\
(\mathrm{km})\end{array}$ & $\begin{array}{c}\mathrm{Vp} \\
(\mathrm{km} / \mathrm{s})\end{array}$ & & $\begin{array}{c}\text { Top Depth } \\
(\mathrm{km})\end{array}$ & $\begin{array}{c}\mathrm{Vp} \\
(\mathrm{km} / \mathrm{s})\end{array}$ \\
\hline 0.00 & 5.20 & & 0.00 & 4.35 \\
2.00 & 6.03 & & 3.00 & 5.85 \\
28.0 & 7.25 & & 18.0 & 6.80 \\
64.0 & 7.90 & & 41.0 & 8.40 \\
75.0 & 8.10 & 60.0 & 8.60 \\
\hline
\end{tabular}



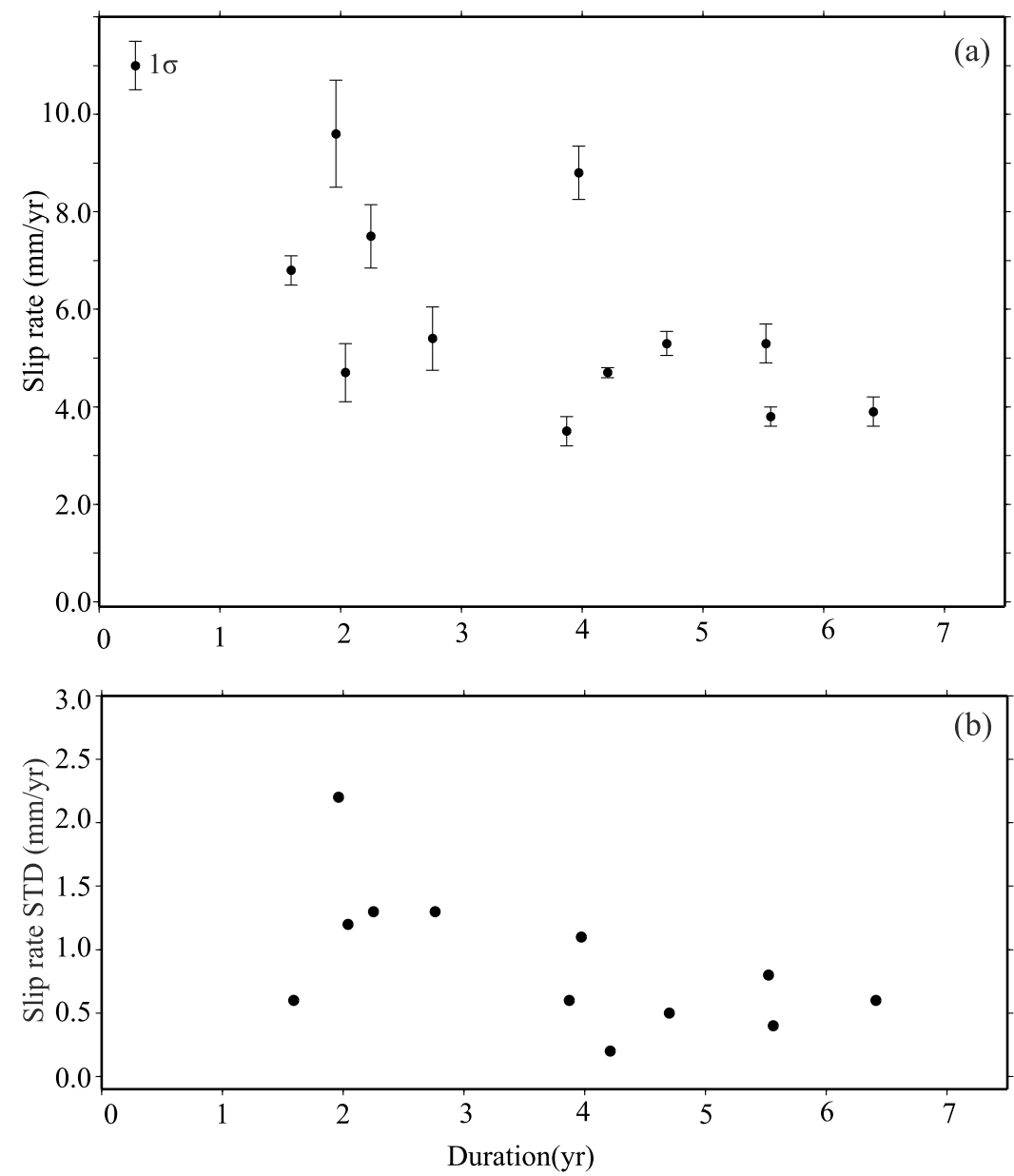

Figure 9. (a) The estimated slip rates and (b) their standard deviations are shown as a function of the sequence duration.

the estimated $M_{0}$ for a magnitude 0.9 and 2.8 events is, respectively, $\sim 40 \%$ lower and $400 \%$ higher than the values computed from equation (6), leading to a $\sim 20 \%$ smaller and $70 \%$ larger estimates in rupture radius, $r$, using equation (7). Since we used rupture radius in selecting repeating events, different estimates in rupture radius could lead to dissimilar assessments in sequence members. For example, with $\mathrm{HK}$ $M_{\mathrm{L}}-M_{0}$ relationship and a $\Delta \sigma=3 \mathrm{MPa}$, sequences $\mathrm{S} 04, \mathrm{~S} 05$, S07 and S09 have one more earthquake (Table 1). For comparison, we also showed the slip rates of the 12 sequences estimated from a combination of $\mathrm{HK}+3 \mathrm{MPa}$ in Table 1 . It appeared that within the uncertainty range the two estimates agree pretty well with each other.

\subsection{Spatial Distribution of Repeating Earthquake Clusters}

[30] In order to determine spatial correspondence between the identified repeating clusters and the asperities within the Longmen Shan fault, we used a modified double-difference method to relocate the entire seismicity, as described in section 3.4. The relocated hypocenters of the repeating earthquake clusters are listed in Table 1. Lateral distribution of the clusters is shown as blue stars in Figure 10. Figure 11 shows the depth distribution of the repeating earthquake clusters along the strike. In general, the slip rates located in shallow area are lower than those in deep area. The highest slip rates are found on the deep portion of the fault, at a depth range of $13-18 \mathrm{~km}$.

\subsection{Relationship With Coseismic Slip}

[31] Finite-fault slip inversion with teleseismic waveform data showed that major rupture of the Wenchuan earthquake occurred near Wenchuan and Pingwu areas with a maximum slip of 6-9 m (C. Ji and G. Hayes, Preliminary result of the May 12, 2008 Mw 7.9 eastern Sichuan, China earthquake, 2008, http://earthquake.usgs.gov/eqcenter/eqinthenews/2008/ us2008ryan/finite_fault.php?, hereinafter Ji and Hayes, online data, 2008) (Figure 11b). Some moderate coseismic slips were observed beneath the Beichuan area. On the other hand, rupture was found to be limited within the uppermost $20 \mathrm{~km}$ of the fault zone. We found that most of the repeating sequences are located at the edge of areas where large coseismic slips were observed (Figure 11). For example, 6 sequences were identified in the Wenchuan area and they are located at either the upper or lower edge of the first sub-event of the earthquake. Three clusters were found in Beichuan region, which showed the same feature. Most of the 12 repeating clusters are located in the Wenchuan area and surround the major rupture zone. It appeared that large coseismic slips near Wenchuan area were supported not only from seismic data, but also from 


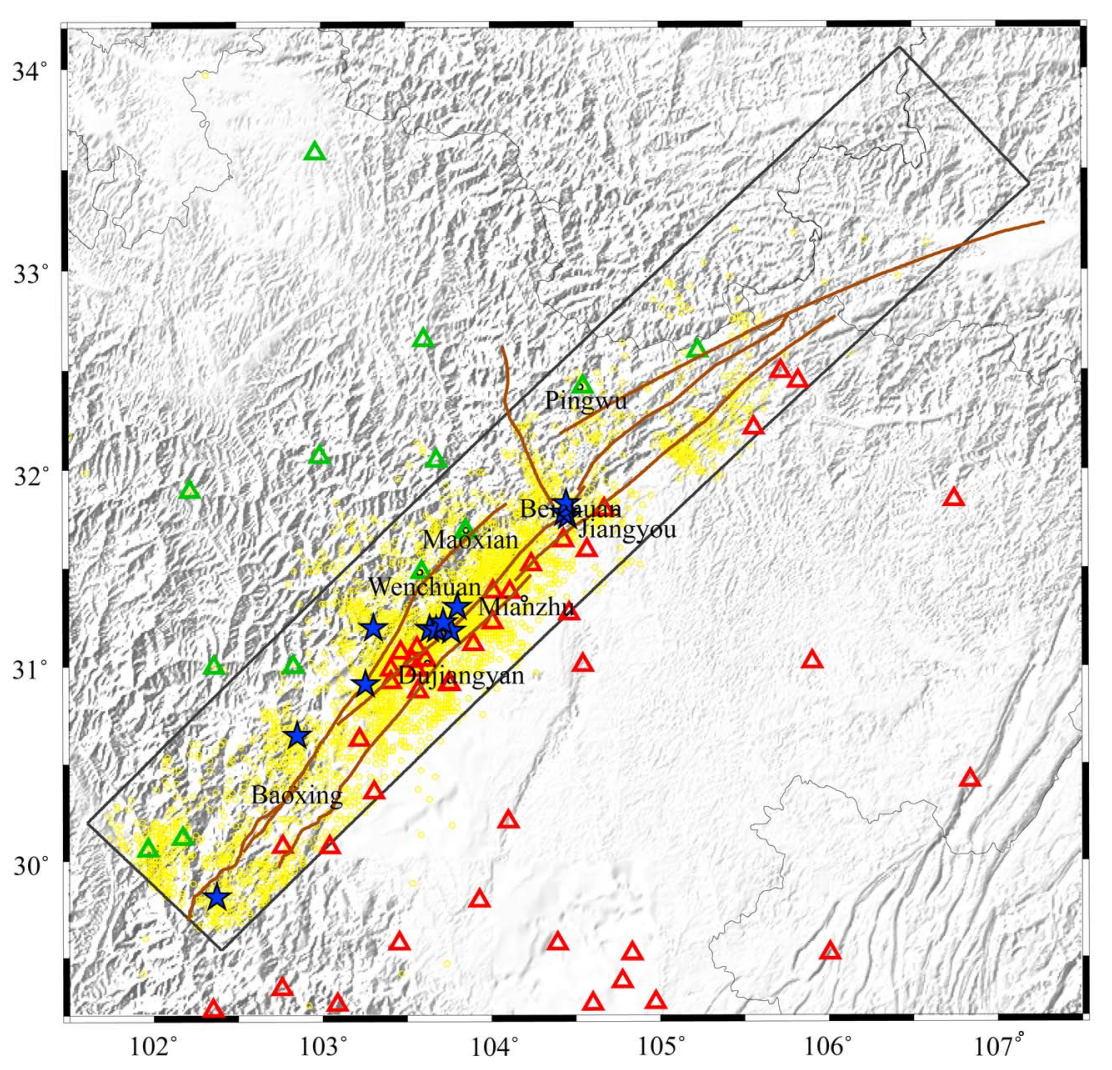

Figure 10. Map view of the repeating earthquake sequences (blue stars) and seismic stations used in relocation (triangles). The green triangles and red triangles represent two groups of stations. Each group shares one velocity model used in hypoDD relocation. Yellow circles indicate the seismicity in study area.

geodetic data (Figure 11b) [Shen et al., 2009]. We thus believe that the observed spatial correlation between the coseismic slip and repeating earthquakes is a robust feature.

[32] The areas with large coseismic slips are known as asperities and locked during the interseismic deformation. The surrounding area, on the other hand, is believed to be relatively weak and may undergo significant aseismic slip between major earthquakes. The repeating microearthquakes thus may represent a few small strong islands in the weak area (Figure 11c). Igarashi et al. [2003] found the same spatial correlation between repeating microearthquakes and asperities of major earthquake at the northeastern Japan subduction zone. Mapping the spatial distribution of repeating earthquake thus provide a way to constrain rupture area for impending earthquakes.

\subsection{Relationship With Seismicity (b-Value)}

[33] Gutenberg and Richter [1944] found that the earthquake size distribution in California follows a power law. The slope of this power law, the 'b-value', is commonly used to describe the relative occurrence of large and small events. Laboratory studies [e.g., Scholz, 1968] found that b values are inversely dependent on differential stress. Recent studies [e.g., Schorlemmer and Wiemer, 2005] confirmed this dependence from field data. We computed the $b$-value distribution across the Longmen Shan fault zone to see whether there is any spatial correlation between the b-value and the distribution of repeating earthquakes.
[34] The catalog we used to calculate b-value distribution includes a total of 15855 events with $M>1.0$ recorded by the SSN between January 1980 and December 2007. We divided the study area with $0.1^{\circ} \times 0.1^{\circ}$ grids. For each grid, we collected earthquakes within $20 \mathrm{~km}$ and used a least square technique to compute the $b$ value if there are more than 100 earthquakes were found around the grid. The estimated $b$ values across the Longmen Shan fault zone are shown in Figure 12a. Two low b-value regions (red color), one at the northeastern end of the fault zone near Pingwu and another in the middle between Mianzhu and Beichuan are clearly shown in the map (Figure 12a). The Pingwu low b-value zone coincided with a large coseismic slip area (Figure 12b), while the central low $\mathrm{b}$-value region appeared to have a low coseismic slip during the Wenchuan earthquake. Thus there seems to be no simple correlation between low b-value and high coseismic slip area, as observed in other region [Schorlemmer and Wiemer, 2005].

[35] The b values in the southwestern segment of the fault zone are relatively high compared to the other segments. It is unclear to us whether this reflects the nature of seismicity, or this is rather related to the network detectability. We noticed there are more seismic stations around the southwestern segment of the fault zone (Figure 10), allowing a better detection of relatively small events that may result in a high $b$ value. For this reason, we also used a more recent catalog (2001 to 2008), the one we used search for repeating events. We simply divided the seismicity into two depth 

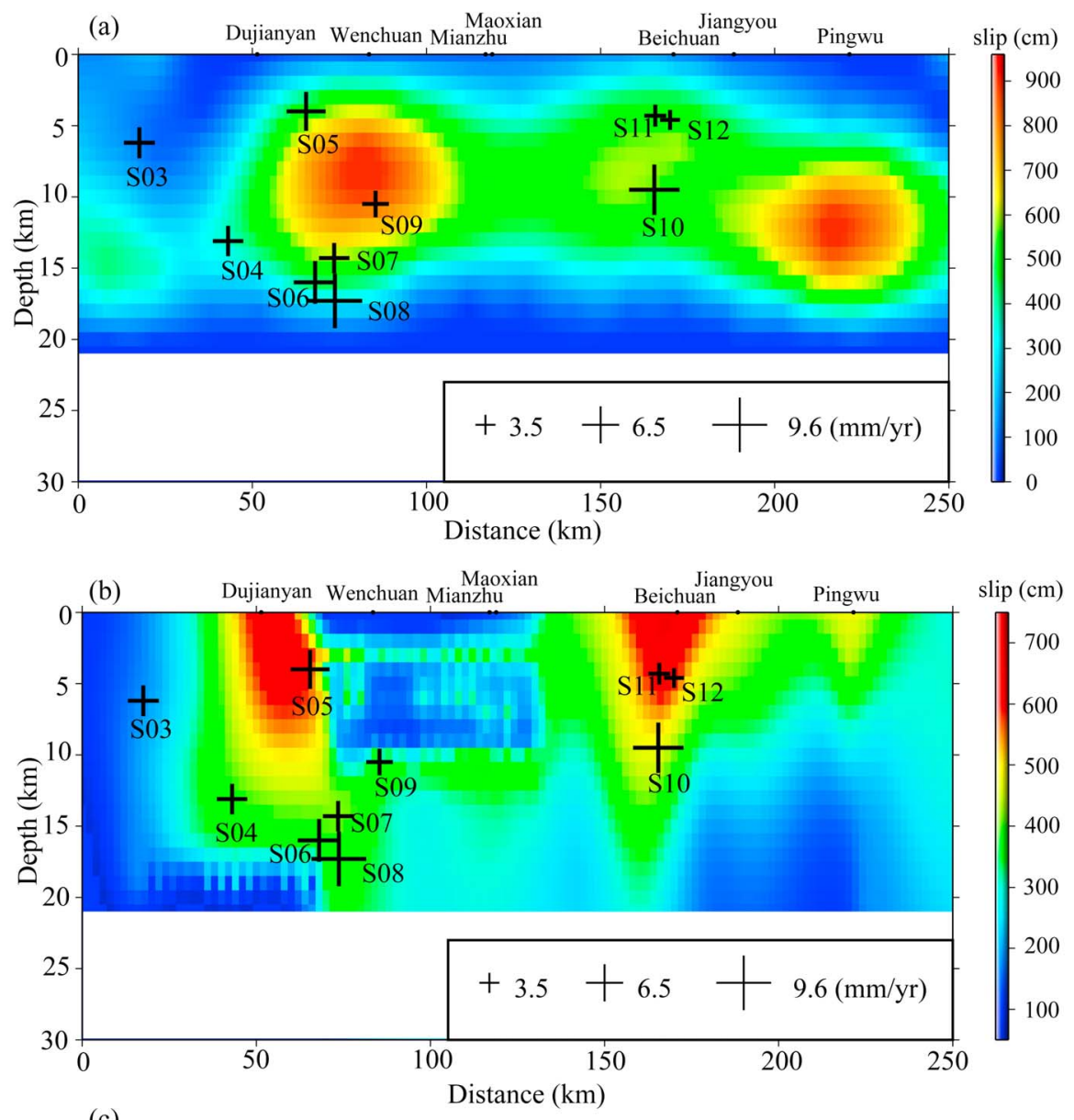

(c)

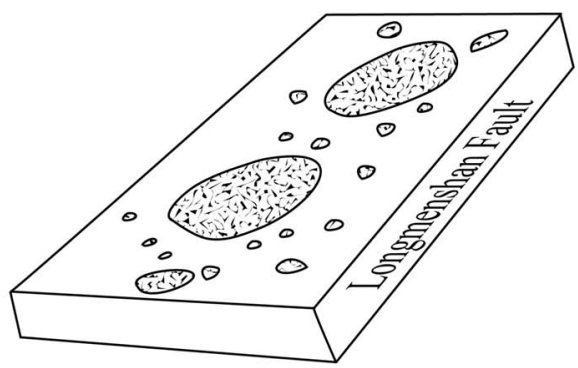

Figure 11. The estimated slip rates are shown together with (a) the coseismic slips inverted from teleseismic waveform data and (b) the coseismic slips inverted from geodetic data. The color scale of slip amplitude is given on the right side of the map. The size of crosses is proportional to the slip rates. (c) A schematic diagram showing the distribution of repeating microearthquakes and asperities of major earthquakes.

groups $(>10$ and $<10 \mathrm{~km}$ ) along the $\mathrm{SW}$ segment of Longmen Shan fault. The $b$ values were computed every $15 \mathrm{~km}$ for each group (Figure 12b). For comparison, we also showed the coseismic slips obtained by $\mathrm{Ji}$ and Hayes (online data, 2008) in Figure 12b. It appears that there is a negative correlation between the b-value and coseismic sip, which agrees with the observation of the 2004 M6 Parkfield earthquake [Schorlemmer and Wiemer, 2005]. We also notice that all the 12 repeating earthquake sequences are located within high $b$-value regions. As high b-value regions are areas prone to small earthquakes, the fault strength may be relatively weak in these regions. This appeared to be consistent with the observation that repeating earthquakes tend to occur near the edges of strong asperities associated with major earthquakes in a fault.

\section{Conclusions}

[36] By cross correlating waveform data recorded by local seismic networks, we found a total of 445 similar earthquakes sequences including 231 doublets and 224 multiplets along the Longmen Shan fault zone where the 2008 M7.9 earthquake occurred. After relocating the relative locations of earthquakes in each multiplet, we identified a total of 

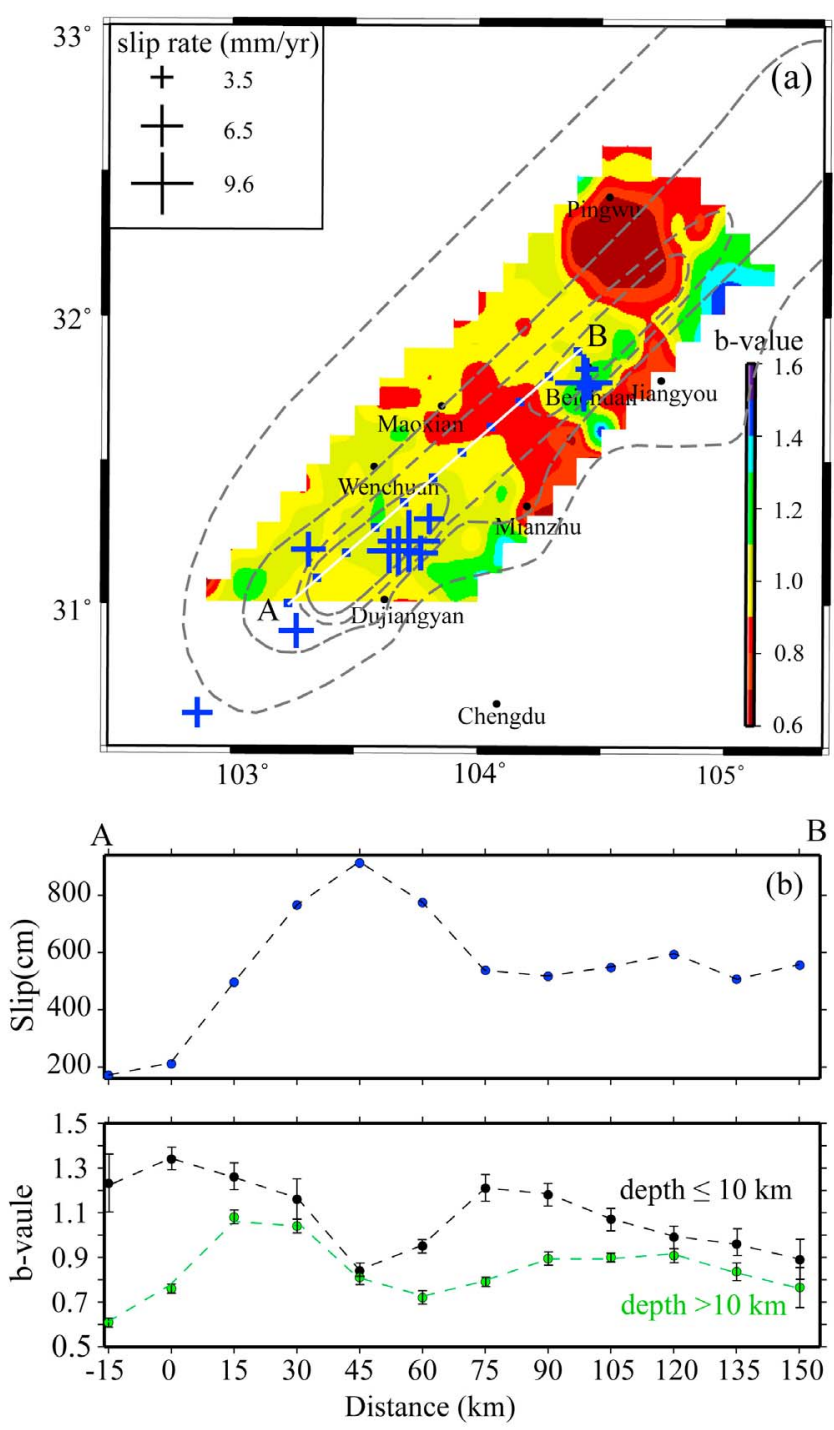

Figure 12. (a) Map view of the estimated b-value across the Longmen Shan fault zone and the 12 repeating earthquake clusters. Grey dashed contour lines show the intensity of the 2008 M7.9 Wenchuan earthquake. The white line $A B$ indicates the location where the $b$ values shown in Figure 12b were calculated. (b) Coseismic slips are shown together with calculated $b$ values along the $A B$ line shown in Figure 12a. Note the negative correlation between the two.

12 earthquake clusters that showed quasiperiodic features of the so-called characteristic events. Most of the sequences are located at the edge of areas with large coseismic slip during the 2008 Wenchuan earthquake. The areas with large coseismic slips also appeared to have low $b$ values. We further used these repeating events to estimate in situ slip rates of the fault at various depths where the repeating earthquakes occurred. Slip rates estimated from the deep clusters tend to be larger than those from the shallow ones. The highest slip rates are found at a depth range of 13 to $18 \mathrm{~km}$. The measured slip rates at depths are about twice as large as those obtained from GPS and geological data. The large deformation rates observed at depth may explain the odds about the occurrence of the unanticipated Wenchuan earthquake. Our observations of repeating earthquakes along the Longmen Shan fault have significant implication in assessing risk of seismic hazard along a fault in terms of constraining the size and recurrence interval of impending earthquakes.

[37] Acknowledgments. We thank the Sichuan Seismic Network of the China Earthquake Administration and the Zipingpu Reservoir Seismic Network for providing the data, Z. Wang for providing crustal velocity models, Y. Huang for providing the revised hypoDD code. Critical comments from two anonymous reviewers and the Associate Editor significantly improved the quality of this paper. This study was supported by China Earthquake Administration grant IES02092405, and NSF grant EAR- 0748455 .

\section{References}

Abercrombie, R. E. (1996), The magnitude-frequency distribution of earthquakes recorded with deep seismometer at Cajon Pass, southern California, Tectonophysics, 261, 1-7, doi:10.1016/0040-1951(96)00052-2.

Beeler, N. M., S. H. Hickman, and T. Wong (2001), Earthquake stress drop and laboratory-inferred interseismic strength recovery, J. Geophys. Res., 106, 30,701-30,713, doi:10.1029/2000JB900242.

Burchfiel, B. C., et al. (2008), A geological and geophysical context for the Wenchuan earthquake of 12 May 2008, Sichuan, People's Republic of China, GSA Today, 18(7), 4-11, doi:10.1130/GSATG18A.1.

Bürgmann, R., D. Schmidt, R. M. Nadeau, M. d'Alessio, E. Fielding, D. Manaker, T. V. McEvilly, and M. H. Murray (2000), Earthquake potential along the northern Hayward fault, California, Science, 289, 1178-1182, doi: $10.1126 /$ science.289.5482.1178

Chen, K. H., R. M. Nadeau, and R. J. Rau (2008), Characteristic repeating earthquakes in an arc-continent collision boundary zone: The Chishang fault of eastern Taiwan, Earth Planet. Sci. Lett., 276, 262-272, doi:10.1016/j.eps1.2008.09.021.

Cheng, X., F. Niu, P. G. Silver, S. Horiuchi, K. Takai, Y. Iio, and H. Ito (2007), Similar microearthquakes observed in western Nagano, Japan, and implications for rupture mechanics, J. Geophys. Res., 112, B04306, doi:10.1029/2006JB004416.

China Earthquake Administration (Ed.) (1999), The Catalogue of Modern Earthquake in China (1912 A.D. -1990 A.D., Ms $\geq 4.7$ ) [in Chinese], China Sci. and Technol. Press, Beijing.

Densmore, A. L., M. A. Ellis, Y. Li, and R. J. Zhou (2007), Active tectonics of the Beichuan and Pengguan faults at the eastern margin of the Tibetan Plateau, Tectonics, 26, TC4005, doi:10.1029/2006TC001987.

Got, J.-L., J. Fréchet, and F. W. Klein (1994), Deep fault plane geometry inferred from multiplet relative relocation beneath the south flank of Kilauea, J. Geophys. Res., 99, 15,375-15,386.

Gutenberg, B., and C. F. Richter (1944), Frequency of earthquakes in California, Bull. Seismol. Soc. Am., 34, 185-188.

Hanks, T. C., and H. Kanamori (1979), A moment magnitude scale, J. Geophys. Res., 84, 2348-2350, doi:10.1029/JB084iB05p02348.

Huang, Y., J. P. Wu, T. Z. Zhang, and D. N. Zhang (2008), Relocation of the M8.0 Wenchuan earthquake and its aftershock sequence, Sci. China, Ser. D Earth Sci., 51, 1703-1711, doi:10.1007/s11430-008-0135-z.

Hubbard, J., and J. H. Shaw (2009), Uplift of the Longmen Shan and Tibetan Plateau, and the 2008 Wenchuan $(\mathrm{M}=7.9)$ earthquake, Nature, 458, 194-197, doi:10.1038/nature07837.

Igarashi, T., T. Matsuzawa, and A. Hasegawa (2003), Repeating earthquakes and interplate aseismic slip in the northeastern Japan subduction zone, J. Geophys. Res., 108(B5), 2249, doi:10.1029/2002JB001920.

Jia, D., Z. Chen, C. Jia, Q. Wei, B. Li, X. Zhang, D. Wei, and Y. Shen (2003), Structural features of the Longmen Shan and thrust belt and development of the western Sichuan foreland basin, Central China [in Chinese], Geol. J. China Univ., 9(3), 402-409.

Kanamori, H., and D. L. Anderson (1975), Theoretical basis for some empirical relations in seismology, Bull. Seismol. Soc. Am., 65, 1073-1095.

Li, L., Q.-F. Chen, X. Cheng, and F. Niu (2007), Spatial clustering and repeating of seismic events observed along the 1976 Tangshan fault, north China, Geophys. Res. Lett., 34, L23309, doi:10.1029/2007GL031594.

Li, L., Q.-F. Chen, F. Niu, R. Liu, and Y. Hou (2009), Slip rate along the Lijiang-Ninglang fault zone estimated from repeating earthquakes, Chin. Sci. Bull., 54(3), 447-455, doi:10.1007/s11434-008-0406-2.

Liu, B., X. Zhang, S. Feng, C. Zhao, J. Ji, J. Shi, and H. Yuan (2009), High-resolution seismic reflection profile across Pengzhou buried fault 
in the frontal areas of Longmen Shan [in Chinese], Chin. J. Geophys., 52 (2), 538-546.

Liu, L., Y. Su, J. Yang, and J. Liu (2010), Study on temporal and spatia features of stress drop for low-to-moderate earthquakes in Sichuan and Yunnan region [in Chinese], J. Seismol. Res., 33, 314-319.

Meade, B. J. (2007), Present-day kinematics at the India-Asia collision zone, Geology, 35, 81-84, doi:10.1130/G22924A.1.

Nadeau, R. M., and L. R. Johnson (1998), Seismological studies at Parkfield VI: Moment release rates and estimates of source parameters for small repeating earthquakes, Bull. Seismol. Soc. Am., 88, 790-814.

Nadeau, R. M., and T. V. McEvilly (1999), Fault slip rates at depth from recurrence intervals of repeating microearthquakes, Science, 285, 718-721, doi:10.1126/science.285.5428.718

Nadeau, R. M., W. Foxall, and T. V. McEvilly (1995), Clustering and periodic recurrence of microearthquakes on the San Andreas fault at Parkfield, California, Science, 267, 503-507, doi:10.1126/science.267.5197.503.

Peng, Z., and Y. Ben-Zion (2006), Temporal changes of shallow seismic velocity around the Karadere-Düzce branch of the north Anatolian fault and strong ground motion, Pure Appl. Geophys., 163, 567-600, doi:10.1007/s00024-005-0034-6.

Peng, Z., J. E. Vidale, C. Marone, and A. Rubin (2005), Systematic variations in recurrence interval and moment of repeating aftershocks, Geophys. Res. Lett., 32, L15301, doi:10.1029/2005GL022626.

Rau, R. J., K. H. Chen, and K.-E. Ching (2007), Repeating earthquakes and seismic potential along the northern Longitudinal Valley fault of eastern Taiwan, Geophys. Res. Lett., 34, L24301, doi:10.1029/2007GL031622.

Royden, L. H., B. C. Burchfiel, and R. D. van der Hilst (2008), The geological evolution of the Tibetan Plateau, Science, 321, 1054-1058, doi:10.1126/ science. 1155371 .

Rubin, A. M., D. Gillard, and J.-L. Got (1999), Streaks of microearthquakes along creeping faults, Nature, 400, 635-641, doi:10.1038/23196.

Schaff, D. P., and P. G. Richards (2004), Repeating seismic events in China, Science, 303, 1176-1178, doi:10.1126/science.1093422.

Schaff, D. P., G. C. Beroza, and B. E. Shaw (1998), Postseismic response of repeating aftershocks, Geophys. Res. Lett., 25, 4549-4553, doi:10.1029/1998GL900192.

Schaff, D. P., G. H. R. Bokelmann, G. C. Beroza, F. Walhauser, and W. L. Ellsworth (2002), High-resolution image of Calaveras fault seismicity, J. Geophys. Res., 107(B9), 2186, doi:10.1029/2001JB000633.

Scholz, C. H. (1968), The frequency-magnitude relation of micro fracturing in rock and its relation to earthquakes, Bull. Seismol. Soc. Am., 58 , 399-415.

Schorlemmer, D., and S. Wiemer (2005), Microseismicity data forecast rupture area, Nature, 434, 1086, doi:10.1038/4341086a.

Shen, Z.-K., J. Lü, M. Wang, and R. Bürgmann (2005), Contemporary crustal deformation around the southeast borderland of the Tibetan Plateau, J. Geophys. Res., 110, B11409, doi:10.1029/2004JB003421.

Shen, Z. K., J. B. Sun, P. Z. Zhang, Y. G. Wan, M. Wang, R. Burgmann, Y. H. Zeng, W. J. Gan, H. Liao, and Q. L. Wang (2009), Slip maxima at fault junctions and rupturing of barriers during the 2008 Wenchuan earthquake, Nat. Geosci., 2, 718-724, doi:10.1038/ngeo636.
Taira, T., P. G. Silver, F. Niu, and R. M. Nadeau (2008), Detecting seismogenic stress evolution and constraining fault-zone rheology in the San Andreas fault following the 2004 Parkfield earthquake, J. Geophys. Res., 113, B03303, doi:10.1029/2007JB005151.

Uchida, N., T. Matsuzawa, A. Hasegawa, and T. Igarashi (2003), Interplate quasi-static slip off Sanriku, NE Japan, estimated from repeating earthquakes, Geophys. Res. Lett., 30(15), 1801, doi:10.1029/2003GL017452.

Vidale, J. E., W. L. Ellsworth, A. Cole, and C. Marone (1994), Variations in rupture process with recurrence interval in a repeated small earthquake, Nature, 36, 8624-8626.

Waldhauser, F., and W. L. Ellsworth (2000), A double-difference earthquake location algorithm: Method and application to the northern Hayward fault, California, Bull. Seismol. Soc. Am., 90, 1353-1368, doi:10.1785 0120000006.

Waldhauser, F., W. L. Ellsworth, and A. Cole (1999), Slip-parallel seismic lineations along the nothern Hayward fault, California, Geophys. Res. Lett., 26, 3525-3528, doi:10.1029/1999GL010462.

Wu, S.-C., C. A. Cornell, and S. R. Winterstein (1995), A hybrid recurrence model and its implication on seismic hazard results, Bull. Seismol. Soc. Am., 85, 1-16.

Xu, X.-W., X. Wen, G. Yu, G. Chen, Y. Klinger, J. Hubbard, and J. Shaw (2009), Coseismic reverse- and oblique-slip surface faulting generated by the $2008 \mathrm{Mw} 7.9$ Wenchuan earthquake, China, Geology, 37, 515-518, doi:10.1130/G25462A.1.

Xu, Z.-Q., S. Ji, H. Li, L. Hou, X. Fu, and Z. Cai (2008), Uplift of the Longmen Shan range and the Wenchuan earthquake, Episodes, 31(3) 291-301.

Zhang, P.-Z., Q. Deng, Q. Zhang, J. Ma, W. Gan, W. Min, F. Mao, and Q. Wang (2003), Active tectonic blocks and strong earthquakes in the continent of China, Sci. China, Ser. D Earth Sci., 46, suppl. 2, 13-24.

Zhang, P.-Z., et al. (2004), Continuous deformation of the Tibetan Plateau from global positioning system data, Geology, 32, 809-812, doi:10.1130/ G20554.1.

Zhang, P.-Z., X. Xu, X. Wen, and Y. Ran (2008), Slip rates and recurrence intervals of the Longmen Shan active fault zone, and tectonic implications for the mechanism of the May 12 Wenchuan earthquake, 2008, Sichuan, China [in Chinese], Chin. J. Geophys., 51(4), 1066-1073.

Zhao, Z., J. Fan, S. Zheng, A. Hasegawa, and S. Horiuchi (1997), Crustal structure and accurate hypocenter determination along the Longmen Shan fault zone, Acta Seismol. Sin., 10(6), 761-768, doi:10.1007/ s11589-997-0008-0.

Q. Chen and L. Li, Institute of Earthquake Science, China Earthquake Administration, P. O. Box 166, No. 63 Fuxing Road, Beijing 10036 , China. (lile@seis.ac.cn)

F. Niu, Department of Earth Science, Rice University, 6100 Main Street, Houston, TX 77005, USA.

J. Su, Earthquake Administration of Sichuan Province, No. 29 Renmin Nanlu Sanduan, Chengdu, Sichuan 610004, China. 